\title{
Signs of an extended and intermittent terminal spawning in the squids Loligo vulgaris Lamarck and Loligo forbesi Steenstrup (Cephalopoda: Loliginidae)
}

\author{
Francisco Rocha*, Angel Guerra \\ Instituto de Investigaciones Marinas (CSIC), C/ Eduardo Cabello 6, 36208 Vigo, Spain
}

Received 5 December 1995; revised 16 April 1996; accepted 3 May 1996

\begin{abstract}
The reproductive pattern of Loligo vulgaris and Loligo forbesi was studied on the basis of gonad maturation, mating and spawning in males and females of both species which were present off the northwest coast of Spain (Galicia), between February 1991 and February 1993. The mature females of both species have several Inodes of egg sizes and developmental stages within the ovary. Several signs indicate that both female Loligo vulgaris and L. forbesi undergo partial ovulation at the time of spawning, the spawning period being relatively long, although in no case representing the greatest fraction of the animal's life before death. Egg-laying occurring in separate batches and somatic growth between egg batchs has not been observed. This reproductive pattern is defined as intermittent terminal spawning. Some other terms describing different cephalopod reproductive strategies are also defined.
\end{abstract}

Keywords: Loligo forbesi; Loligo vulgaris; NW Atlantic; Reproduction; Spawning patterns

\section{Introduction}

Until recently, it was generally accepted that female cephalopods lay their eggs in one single spawning or in several consecutive ones, with no pause between each, after which they would die by exhaustion (McGowan, 1954; Mangold, 1987; Harman et al., 1989; Mangold et al., 1993). The animals with this reproductive pattern where gonad regeneration is absent are known as semelparous. Conversely, the iteroparous species are those in which a gonadal regeneration following spawning occurs, making new reproductive cycles possible.

*Conresponding author. Tel.: +34 86 231930; Fax: +3486292762 
As knowledge has grown regarding the biology of this group, it has become increasingly difficult to support the notion of a single reproductive pattern (Boletzky, 1981, Boletzky, 1986; Rodaniche, 1984; Harman et al., 1989; Mangold et al., 1993). A case in point is Nautilus, with a life span of 20 years, which must be considered as an iteroparous species since the females spawn once a year, surviving, feeding, growing and regenerating their gonads for a further reproductive event the following year (Ward, 1987). With the exception of this particular case, the other cephalopods may be considered as semelparous, although there are significant differences between the maturation processes and spawning from one species to another (Boletzky, 1975; Mangold, 1987; Mangold et al., 1993). According to these differences, several reproductive strategies may be defined in cephalopods with regard to the oocyte maturation process and to the type of spawning process in each species (Boletzky, 1981, Boletzky, 1986; Harman et al., 1989; Villanueva, 1992; Mangold et al., 1993; González, 1994; Rocha, 1994; Rasero, 1996). The current definitions for the different reproductive cephalopod strategies are confused. For clarity and accuracy the reproductive terms used in this paper are defined.

'Simultaneous terminal spawning'. This is a type of spawning where ovulation is synchroneous, egg-laying occurs in a very short period at the end of the animal's life before death, and there is not oocyte maturation during spawning period. Several species have been found which exhibit simultaneous terminal spawning, e.g. Loligo opalescens, Illex illecebrosus and Todarodes pacificus (Hixon, 1983; O’Dor, 1983; Ikeda et al., 1993). This type of spawning is also called 'terminal spawning' and 'single spawning' (Hixon, 1983; Mangold et al., 1993).

'Intermittent terminal spawning'. In this type of spawning 'partial ovulation' occurs. Partial ovulation implies the presence of oocytes at various stages of development in the ovaries, thus enabling the continued production of ova once spawning has commenced. Partial ovulation has been described in several species: Sthenoteuthis oualaniensis, Loligo bleekeri and Idiosepius pygmaeus (Harman et al., 1989; Hun Baeg et al., 1993; Lewis and Choat, 1993). In the intermittent terminal spawning egg-laying occurs in separate batches during the spawning period which is usually relatively long, although in no case does it represent the greatest fraction of the animal's life before death. The species Loligo vulgaris reynaudii and L. bleekeri (Sauer and Lipinski, 1990; Hun Baeg et al., 1993) seem to be intermittent terminal spawners in which growth does not take place between separate egg batches, egg batches includes ripening of eggs and subsecuent deposition. This type of spawning corresponds to 'intermittent spawning' defined by Boletzky (1975). A modality of the intermittent terminal spawning is the 'multiple spawning' (Harman et al., 1989), when somatic growth occurs between separate egg batches. Several species have been found which exhibit multiple spawning, e.g. Octopus chierchiae, Sepia officinalis and Sthenoteuthis oualaniensis (Rodaniche, 1984; Boletzky, 1975: Boletzky, 1987; Boletzky, 1988; Harman et al., 1989; Forsythe et al., 1991).

Another type of reproductive strategy was found in the cirrate octopods Opisthoteuthis agassizii and $O$. vossi. This strategy is the 'continuous spawning', which was named and defined by Villanueva (1992).

The patterns of ovulation and spawning in Loligo vulgaris have received little 
attention. Mangold-Wirz (1963), Worms (1983), Baddyr (1988), Coelho et al. (1994), Guerra and Rocha (1994), Moreno et al. (1994) and Arkhipkin (1995) described that the species has an extended spawning period, but only Guerra and Rocha (1994) have suggested that $L$. vulgaris could be an intermittent spawner. In the case of Loligo forbesi the evidence of an extended breeding scason was also shown (Lum-Kong et al., 1992; Boyle and Ngoile, 1993; Guerra and Rocha, 1994; Moreno et al., 1994; Pierce et al., 1994; Boyle et al., 1995; Collins et al., 1995b). While Lum-Kong (1993) indicated continuous spawning for this species, Boyle et al. (1995), Guerra and Rocha (1994) and Collins et al. (1995a), (1995b) suggested intermittent spawning.

This study examines the reproductive pattern presented by both sexes of Loligo vulgaris and $L$. forbesi in the waters off NW Spain, thus completing the study of various aspects of the reproductive biology of both sexes of these species begun by Guerra and Rocha, 1994, particularly with regards to the duration of breeding period and types of ovulation and spawning.

\section{Materials and methods}

A total of 1,787 individuals of Loligo vulgaris were studied (862 males and 925 females), and 755 Loligo forbesi (399 males and 356 females), with a dorsal mantle lengths (ML) between 98 and $475 \mathrm{~mm} \mathrm{ML}$ in Loligo vulgaris and 100 and $685 \mathrm{~mm} \mathrm{ML}$ in Loligo forbesi. The individuals were obtained from monthly samples from commercial catches landed at ports and fishing sites in Galicia, between February 1991 and February 1993. Samples were frozen al $-30^{\circ} \mathrm{C}$, duly labelled and preserved for subsequent laboratory analysis. The individuals were defrosted at room temperature, their sex was determined and total weight (BW) and dorsal mantle length (ML) noted. Measurements were made in millimetres and grammes, with a margin of error of $\pm 0.5 \mathrm{~mm}$ and \pm 0.01 $\mathrm{g}$, respectively.

Maturity in males and females was estimated using a 5 stage maturity scale, as indicated by Boyle and Ngoile (1993). In this scale, stages IV and V represent squid in breeding condition and hence, part of the spawning stock. A gonad-somatic index (GSI) was calculated as follows:

$$
\mathrm{GSI}=\frac{\mathrm{GW}}{\mathrm{BW}} * 100
$$

where GW is the weight of the gonad (testis or ovary).

In females the reproductive system was dissected, and the ovary (OW), the oviducal complex (oviducts, nidamental glands and accessory reproductive glands) (OCW), the proximal oviduct (POW) and the nidamental glands (NGW) were weighed separately. In males, the reproductive system was dissected, and the weights of the testis (TW) and to the spermatophoric complex (SCW) determined.

Female fecundity was estimated for mature individuals (stages IV and V), based on subsamples of ovary and proximal oviduct from the distal and medial zones weighing $0.3-1.0 \mathrm{~g}$. Each sample was weighed and preserved in Gilson solution, the oocytes from the sample having been released from the surrounding tissue by brusque movements in 
water. The oocytes present in each ovary and oviduct subsample were counted, measuring the largest diameter using a binocular microscope with an ocular micrometer. Damaged or deformed oocytes were not measured. The size distribution of oocytes in the ovaries of both species was subjected to a size frequency distribution analysis using the method of Bhattacharya (1967) to check for the presence of different size groups. The Bhattacharya method, as implemented in the ELEFAN software (Gayanilo et al., 1989) was used to identify putative size groups within size distribution of oocytes in each ovary. The method assumes that the size of oocytes within each size group is normally distributed. An interactive routine is used to define the component size groups, with goodness of fit assessed by $X^{2}$ tests.

The spermatophoric complex from mature males (stages IV and V) of different sizes was labeled and preserved in formalin (5\%). A subsample of each complex was weighed, counting the spermatophores which they contained and measuring the spermatophore length (SL). Deteriorated spermatophores were excluded from the measuring. In each case, the total number of spermatophores (SN) was estimated from the measured subsample.

\section{Results}

In mature male and female of Loligo vulgaris and L. forbesi a large variation in the GSI/ML ratio was found (Fig. 1). In both species and sexes, the GSI decreased with the increasing in ML.

In stage V male Loligo vulgaris, a large variation in the SCW/BW ratio was observed relative to ML (Fig. 2a). Individuals below $380 \mathrm{~mm}$ ML had GSI greater than $1.3 \%$, whereas larger squid has GSI less than $1.3 \%$ (Fig. 2a). There was also a large variation between the SL and the SCW/BW (Fig. 2b). It was observed, however, that individuals with a GSI above $1.3 \%$ had smaller spermatophores than those with a GSI below $1.3 \%$ (Fig. 2b). Between specimens of a range of SL $(13-17 \mathrm{~mm})$, those with a GSI above $1.3 \%$ showed larger spermatophoric complexes.

In stage V male Loligo forbesi, a gradual decrease in the SCW/BW ratio was found, relative to the ML (Fig. 3a). Males with a GSI of over $1.3 \%$ were present at sizes below $410 \mathrm{~mm}$ ML, whereas those with a GSI below $1.3 \%$ had sizes above $410 \mathrm{~mm}$ ML and smaller spermatophoric complexes (Fig. 3a). The SCW also decreased with the SL (Fig. $3 \mathrm{~b})$. It was noted that male $L$. forbesi with a GSI above $1.3 \%$ presented a larger complex and smaller sized spermatophores than the males with a GSI below $1.3 \%$ (Fig. $3 \mathrm{~b}$ ).

The diameter of oocytes in Loligo vulgaris ovaries varied between 0.1 and $4.1 \mathrm{~mm}$, whereas in female L. forbesi, the range was between 0.1 and $4.3 \mathrm{~mm}$. In both species, the mature female ovaries of all the sizes studied showed slightly different polymodal distributions of oocytes, depending on the individual examined (Fig. 4). Because the distribution of diameters in oocytes in each ovary varies from individual to individual within the same species, mean sizes and the standard deviations for each species are plotted as shown in Fig. 5. Analysis of size distribution of oocytes in the ovaries of 9 female $L$. vulgaris showed the presence of 3 to 5 modal groups of oocytes, depending on 

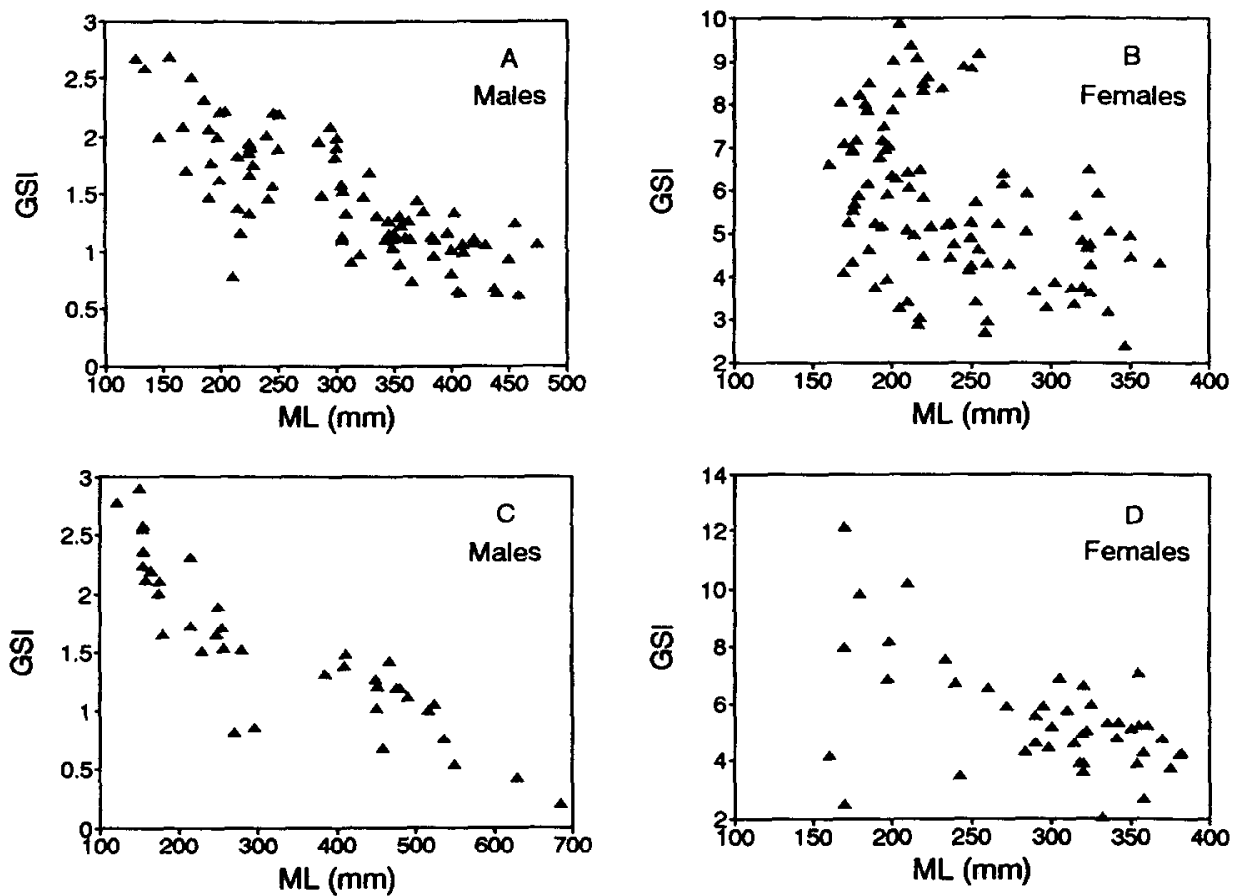

Fig. 1. Relationship between the dorsal mantle length (ML) and the gonad-somatic index (GSI) in mature male and female of Loligo vulgaris (A and $\mathrm{B}$ ) and Loligo forbesi (C and D), respectively.

the individual studied. A minimum of 3 and a maximum of 7 modal size groups of oocytes were found in the ovaries of 14 mature female $L$. forbesi (Table 1 ).

The mean size of oocytes in the proximal oviduct of $L$. vulgaris $(2.74 \mathrm{~mm} ; \mathrm{SD}=1.54$ $\mathrm{mm})$ and $L$. forbesi $(3.06 \mathrm{~mm} ; \mathrm{SD}=0.28 \mathrm{~mm})$ is indicated in Fig. 5 . The number of oocytes in the proximal oviduct of mature females in both species varied directly with ML (Fig. 6). In L. vulgaris, the maximum number of oocytes present was 10,000, whereas in $L$. forbesi, the number rose to 4,700 .

Nidamental gland weight (NGW) increased with size in females of both species (Fig. 7). In the case of females with GSI below 4.0, however, this weight was less than that for females of the same size, with an average GSI of between 4.0 and 7.0, or of over 7.0. This relationship was exponential in each case (Table 2).

\section{Discussion}

The presence of small (ML $<380 \mathrm{~mm}$ ) mature male Loligo vulgaris with small spermatophores, GSI $>1.3$, and highly variable SCW/BW ratio, together with large mature male $L$. vulgaris with big spermatophores, GSI $<1.3$, and the same variability in SCW/BW ratio that formers, could be explained in two different ways: 1) Sper- 

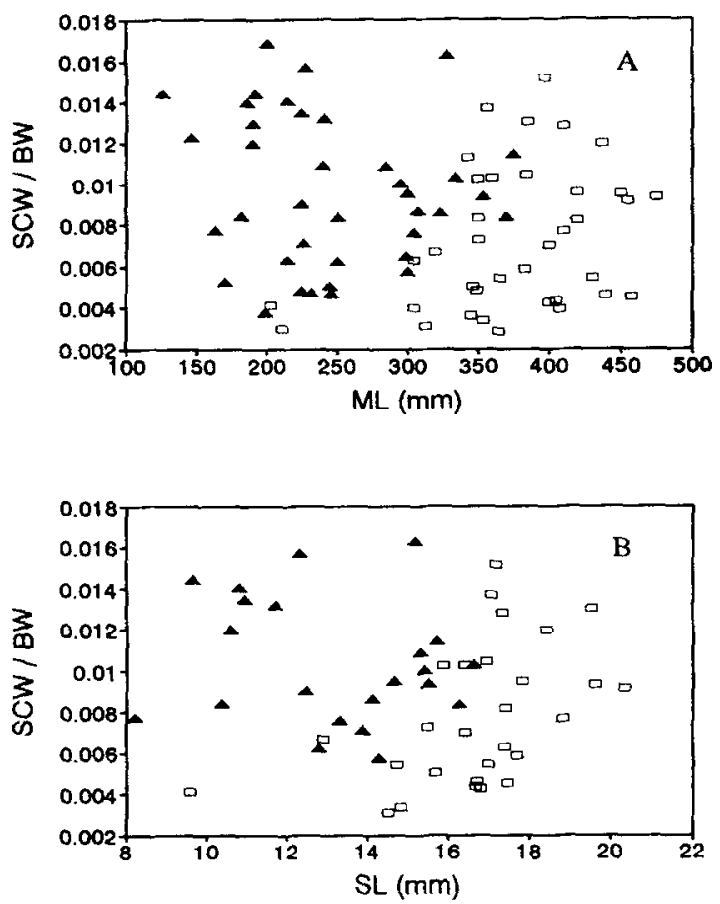

Fig. 2. Relationship between the dorsal mantle length (ML) and the ratio spermatophoric complex weight (SCW)/Body Weight (BW) (A) and between spermatophore length (SL) and the SCW/BW (B) in male Loligo vulgaris at stage $\mathrm{V}$ of maturity. $\boldsymbol{\Lambda}$, GSI above $1.3 \% ; \square$, GSI of below $1.3 \%$

matophores may be produced throughout the prolonged mating period resulting in depletion of the testis. Since the SL/ML ratio is linear (Guerra and Rocha, 1994), the length of the spermatophores increased in the same given mature animal while it is growing somatically. 2) The existence of two groups of squid at maturity, the younger and smaller ones having relatively large gonads, the large older ones having smaller gonads, but larger spermatophores. If large maturity size is achieved at the expense of reproductive investment, then one might expect to see the smaller GSI in the larger mature squid. These two groups of squid at maturity found in the species by Coelho et al. (1994) and Guerra and Rocha (1994) seems to be represented by animals of different ages (Rocha, 1994; Rocha and Guerra, in prep.).

In stage $\mathrm{V}$ male Loligo forbesi of maturity, SCW/BW varied among individuals of the same ML, gradualy decreasing as ML increased. GSI also decreased when ML increased. The existence of two size groups of squid at maturity (Guerra and Rocha, 1994; Boyle et al., 1995; Collins et al., 1995a) is a better argument than somatic growth during mating to explain the reproductive pattern found in males of this species because the gradual decrease in SCW/BW vs ML relationship (Fig. 3). On the contrary that in $L$. vulgaris, these two groups of $L$. forbesi at maturity seems to be represented by animals 

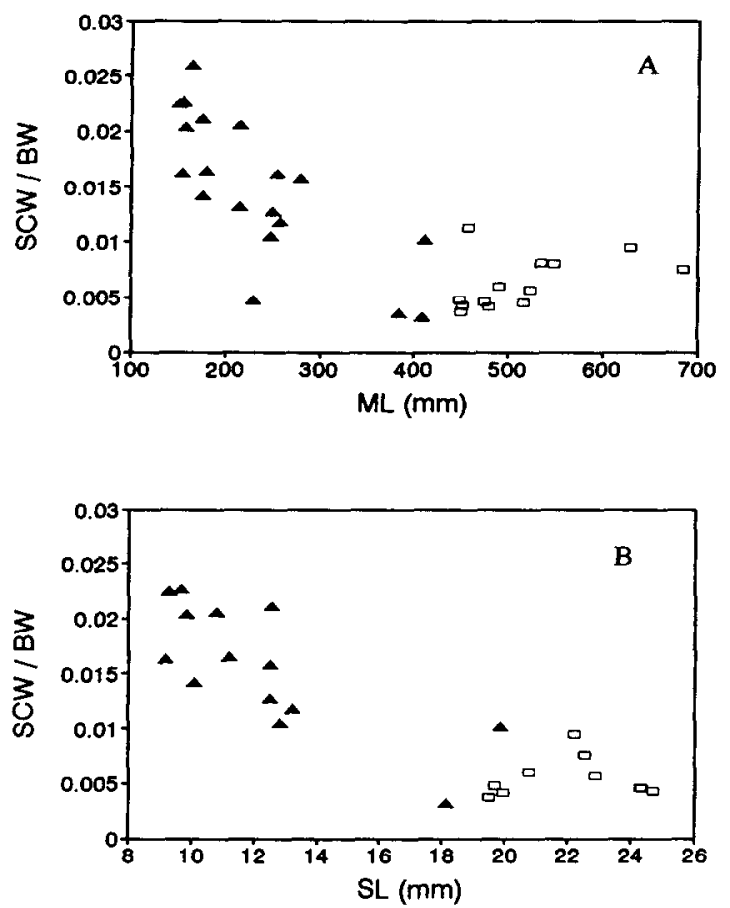

Fig. 3. Relationship between the dorsal mantle length (ML) and the ratio spermatophoric complex weight (SCW)/Body Weight (BW) (A) and between spermatophore length (SL) and SCW/BW (B) in male Loligo forbesi at stage $\mathrm{V}$ of maturity. $\boldsymbol{\Lambda}$, GSI above $1.3 \%$; $\square$, GSI of below $1.3 \%$.

of similar ages, although further ageing analysis are necessaries (Rocha, 1994; Boyle et al., 1995; Rocha and Guerra, in prep.).

The discrepancy between the size categories of the oocytes in the ovaries of both species noted in Guerra and Rocha (1994) and the ones presented here is due to that the size distribution of oocytes in the ovaries has been analysed more accurately, avoiding the previous imprecise clasification into three categories (large, medium and small oocytes).

The presence of an asynchroneous development in loliginid oocytes was histologically shown in Loligo vulgaris reynaudii (Sauer and Lipinski, 1990) and in L. bleekeri (Hun Baeg et al., 1993), and it suggest that both species spawn intermittently.

The size distribution of ovarian oocytes in Loligo forbesi at different stage of maturity shown by Lum-Kong (1993) led her to suggest that spawning is continous in that species. But, from our view, Lum-Kong's data are not sufficient to support that continous spawning is occurring in L. forbesi. When the oocyte distribution of more than one specimen is added and then analysed, as was done by this author (comparc Fig. 4 and Fig. 5), the presence of dominant size modes vanish. Moreover, the mere presence of oocytes at different stages of maturity during the spawning process is insufficient to 

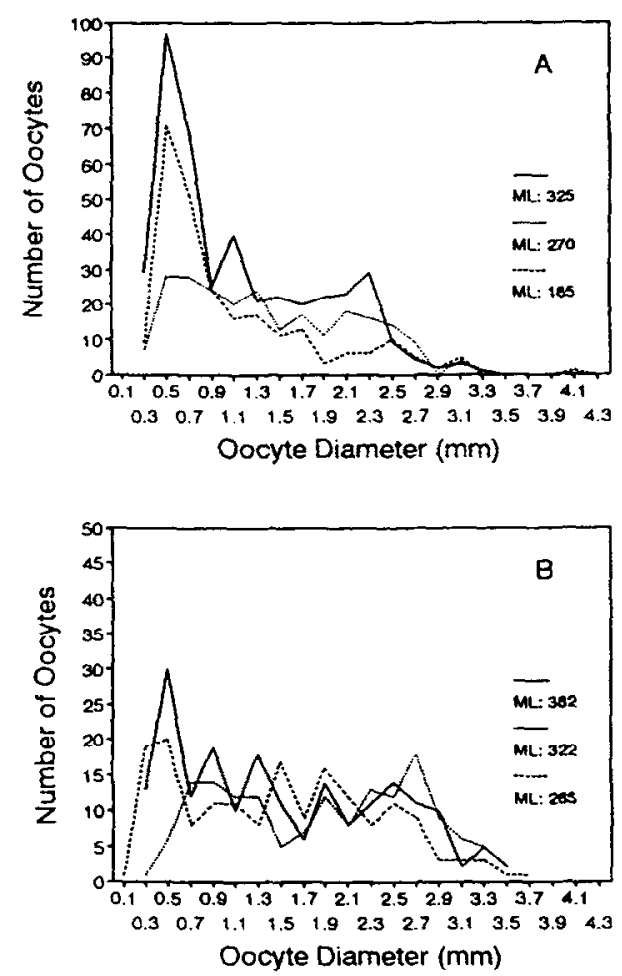

Fig. 4. Frequency distribution of oocytes in the ovary of three individuals of Loligo vulgaris (A) and Loligo forbesi (B), with to size intervals of $0.2 \mathrm{~mm}$ (in the figure, the upper limit of the interval is shown). ML: Dorsal Mantle Length.

identified any species as multiple spawning (Mangold et al., 1993). This because multiple spawning implies that somatic growth occurs between separate egg batches (Harman et al., 1989), which was not observed in the case of Loligo vulgaris and $L$. forbesi.

These two loliginid squid may not be either considered as simultaneous terminal spawners. In a simultaneous terminal spawning species, the majority of oocyte production must be available for egg-laying within a very brief period of time (Jackson and Mladenov, 1994); this occurs in Loligo opalescens (McGowan, 1954; Knipe and Beeman, 1978), but in L. vulgaris and L. forbesi, this is very improbable due to the fact that all the oocytes do not mature at the same time (partial ovulation), and that the oviduct would be unable to manage the entire production all at once.

There are also several signs in Loligo vulgaris and L. forbesi which support the existence of multiple spawning in Sthenoteuthis oualaniensis (Harman et al., 1989), but they are not, however, clear evidences of multiple spawning nor of intermittent spawning. These signs arc: (a) the wide variation in the total number of oocytes in the oviduct and ovary in females at the same stage of maturity and of the same ML. This might also be explained, however, by a variable growth rate, which is well documented 

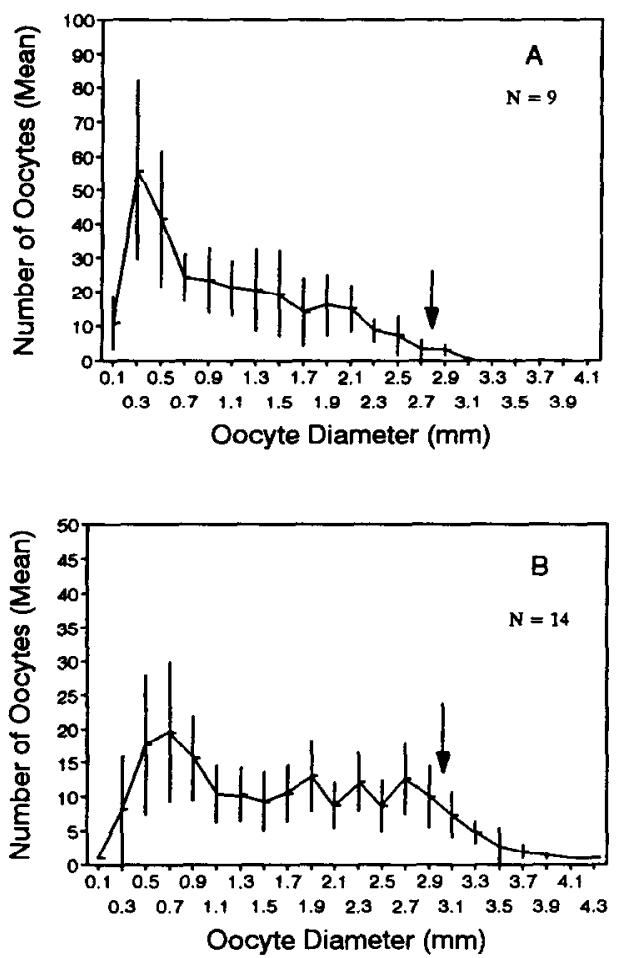

Fig. 5. Average distribution of diameters of oocytes and standard deviation in the ovary of mature Loligo vulgaris (A) and Loligo forbesi (B) females, with size intervals of $0.2 \mathrm{~mm}$ (in the figure, the upper limit of the interval is shown). N: Number of ovaries examined; Arrow: Mean size of oocytes in proximal oviduct.

in both loliginid species (Natsukari and Komine, 1992; Guerra and Rocha, 1994; Arkhipkin, 1995; Collins et al., 1995c), where some females might be expected to mature earlier than others; (b) the wide ML range covered by stages IV and V of maturity in Loligo vulgaris and L. forbesi (Guerra and Rocha, 1994). Again, this point may be similarly explained by the fact that there is reasonable evidence for two size

Table 1

Number of oocyte modal size groups found in ovaries of Loligo vulgaris and Loligo forbesi by polymodal analysis

\begin{tabular}{lll}
$\begin{array}{l}\text { Modal } \\
\text { sizes }\end{array}$ & $\begin{array}{l}\text { Loligo vulgaris } \\
\text { Percentage }\end{array}$ & $\begin{array}{l}\text { Loligo forbesi } \\
\text { Percentage }\end{array}$ \\
\hline 3 & 44.5 & 7.1 \\
4 & 33.3 & 42.9 \\
5 & 22.2 & 35.8 \\
6 & - & 7.1 \\
7 & - & 7.1 \\
\hline
\end{tabular}



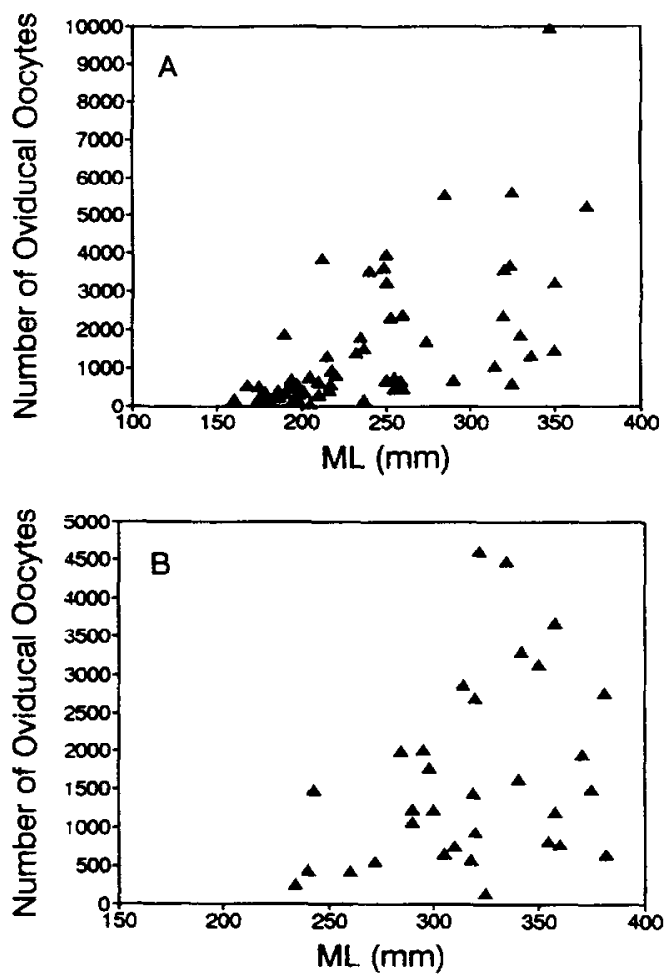

Fig. 6. Relationship between the dorsal mantle length (ML) and the number of oocytes present in the proximal oviduct of Loligo vulgaris (A) and Loligo forbesi (B).

modes of mature males and females in both species (Coelho et al., 1994; Guerra and Rocha, 1994; Boyle et al., 1995; Collins et al., 1995a).

The decrease of the NGW and GSI respect to ML observed (Fig. 7) could be explained as a fall in the NGW after a spawning event. It remains to be seen, however, whether nidamental gland weight would decrease in females which have spawned on one or more than one occasion prior to being caught.

In conclusion, evidence strongly supports extended and intermittent terminal spawning in Loligo vulgaris and L. forbesi, as suggested by Guerra and Rocha (1994), Collins et al. (1995a) and Boyle et al. (1995) although evidence for multiple spawning is minimal.

\section{Acknowledgments}

We thank Mr F. Casas and Mrs M.T. Fernández for their invaluable technical assistance and B.G. Castro, A.F. González and M. Rasero, members of the Vigo Cephalopod Ecophysiology Group, for their comments and suggestions. We also wish to express our gratitude to Dr. Sigurd von Boletzky and an anonimous referee for their 

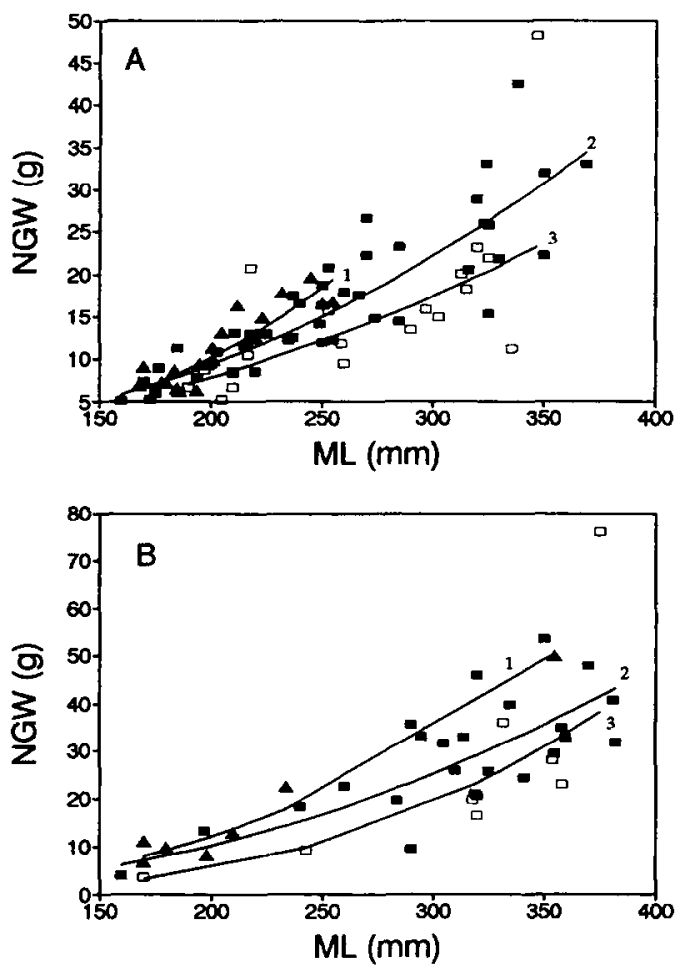

Fig. 7. Relationship between the dorsal mantle length (ML) and nidamental gland weight (NGW) in mature female Loligo vulgaris (A) and Loligo forbesi (B), according to their GSI. $\mathbf{A}$, GSI $\geq 7.0(1) ; \mathbf{\square}, 4.0 \leq \mathrm{GSI}<7.0$ (2); $\square$, GSI $<4.0(3)$.

helpful corrections to the manuscript. We would also like to thank Ian Emmett for the English translation of the text. This work was financed by two projects under the auspices of the European Union (FAR, MA.1.146 and AIR1-CT92-0573).

Table 2

The relationship between the nidamental gland weight (NGW) and dorsal mantle length (ML) in mature female Ioligo vulgaris and Ioligo forhesi, according to the Gonad-somatic index (GSI)

\begin{tabular}{lrrrr}
\hline & $\mathrm{a}$ & $\mathrm{b}$ & $\mathrm{r}^{2}$ & $\mathrm{~N}$ \\
\hline Loligo vulgaris & & & & \\
GSI $\geq 7.0$ & 0.0000062 & 2.699 & 0.77 & 22 \\
$4.0 \leq \mathrm{GSI}<7.0$ & 0.0001151 & 2.134 & 0.83 & 49 \\
GSI $<4.0$ & 0.0002112 & 1.985 & 0.56 & 18 \\
& & & & \\
Loligo forbesi & & & & \\
GSI $\geq 7.0$ & 0.0000228 & 2.488 & 0.88 & 7 \\
$4.0 \leq$ GSI $<7.0$ & 0.0000719 & 2.238 & 0.67 & 23 \\
GSI $<4.0$ & 0.0000004 & 3.117 & 0.86 & 9 \\
\hline
\end{tabular}

Equation: $W=\mathrm{aL}^{\mathrm{b}} ; \mathrm{r}^{2}$ : determination coefficient; $\mathrm{N}$ : number of individuals. 


\section{References}

Arkhipkin, A., 1995. Age, growth and maturation of the european squid Loligo vulgaris (Myopsida, Loliginidae) on the west Sahara shelf. J. Mar. Biol. Ass. U.K., Vol. 75, pp. 593-604.

Baddyr, M., 1988. The biology of the squid Loligo vulgaris in relation to the artisanal fishing site of Tifnit, Moroceo. Doctoral Thesis, Institut Agronomique et Vètèrinaire Hassan II. Rabat, 93 pp.

Bhattacharya, C.G., 1967. A simple method of resolution of a distribution into Gaussian components. Biometrics, Vol. 23, pp. 115-125.

Boletzky, S. von, 1975. The reproductive cycle of Sepiolidae (Mollusca, Cephalopoda). Pubbl. Staz. Zool. Napoli, Vol. 39 Suppl., pp. 84-95.

Boletzky, S. von, 1981. Réflexions sur les stratégies de reproduction chez les Céphalopodes. Bull. Soc. Zool. Fr., Vol. 106, pp. 293-304.

Boletzky, S. von, 1986. Reproductive strategies in cephalopods: variation and flexibility of the life-history patterns. In, Advances in Invertebrate Reproduction, edited by M. Porchet, J.C. Andries and A. Dhainaut, Elsevier, Vol. 4, pp. 379-389.

Boletzky, S. von, 1987. Fecundity variation in relation to intermittent or chronic spawning in the cuttlefish, Sepia officinalis L. (Mollusca, Cephalopoda). Bull. Mar. Sci., Vol. 40, pp. 382-387.

Boletzky, S. von, 1988. A new record of long-continued spawning in Sepia officinalis (Mollusca, Cephalopoda). Rapp. Comm. Int. Mer Médit., Vol, 31, pp. 257.

Boyle, P.R. and M.A.K. Ngoile, 1993. Assessment of maturity state and seasonality of reproduction in Loligo forbesi (Cephalopoda: Loliginidae) from Scottish waters. In: Recent advances in fisheries biology, edited by T. Okutani, R.K. O’Dor and T. Kubodera, Tokai University Press, Tokyo, pp. 37-48.

Boyle, P.R., G.J. Pierce, and L.C. Hastie, 1995. Flexible reproductive strategies in the squid Loligo forbesi. Mar. Biol., Vol. 121, pp. 501-508.

Coelho, M.L., J. Quintela, V. Bettencourt, G. Olavo and H. Villa, 1994. Population structure, maturation patterns and fecundity of the squid Loligo vulgaris from southern Portugal. Fish. Res., Vol. 21, pp. 87-102.

Collins, M.A., G.M. Burnell and P.G. Rodhouse, 1995a. Reproductive strategies of male and female Loligo forbesi (Cephalopoda: Loliginidae). J. Mar. Biol. Ass. U.K., Vol. 75, pp. 621-634.

Collins, M.A., G.M. Burnell and P.G. Rodhouse, 1995b. Recruitment, maturation and spawning of Loligo forbesi Steenstrup (Cephalopoda: Loliginidae) in Irish waters. ICES J. Mar. Sci., Vol. 52, pp. 127-137.

Collins, M.A., G.M. Burnell and P.G. Rodhouse, 1995c. Age and growth of the squid Loligo forbesi (Cephalopoda: Loliginidae) in Irish waters. J. Mar. Biol. Ass. U.K., Vol. 75, pp. 605-620.

Forythe, J.W., R.T. Hanlon and R. DeRusha, 1991. Pilot large-scale culture of Sepiain biomedical research. In: The Cuttlefish, edited by E. Boucaud-Camou, Centre de Publications de l'Université de Caen, pp. 313-323.

Gayanilo, F.C.Jr., M. Soriano and D. Pauly. 1989. A draft guide to the compleat ELEFAN software. ICLARM Contrib., Vol. 435, 70 pp.

González, A.F., 1994. Bioecología de Illex coindetti (Vérany, 1839) (Cephalopoda, Ommastrephidae) de las aguas de Galicia. Doctoral Thesis, University of Vigo. Vigo, Spain. 237 pp.

Guerra, A. and F. Rocha, 1994. The life history of Loligo vulgaris and Loligo forbesi (Cephalopoda: Loliginidae) in Galician Waters (NW Spain). Fish. Res., Vol. 21, pp. 43-69.

Harman, R.F., R.E. Young, K.M. Mangold, T. Suzuki and R.F. Hixon, 1989. Evidences for multiple spawning in the tropical oceanic squid Sthenoteuthis oualantensis (leuthoidea: Ommastrephidae). Mar. Biol., Vol. 101, pp. 513-519

Hixon, R.F., 1983. Loligo opalescens. In: Cephalopods Life Cycles, edited by P.R. Boyle, Academic Press, London, Vol. 1. Species account, pp. 95-114.

Hun Baeg, G., Y. Sakurai and K. Shimazaki, 1993. Maturation Processes in female Loligo bleekeri Keferstein (Mollusca: Cephalopoda). Veliger, Vol. 36, pp. 228-235

Ikeda, Y., Y. Sakuray and K. Shimazaki, 1993. Maturation process of the Japanese common squid Todarodes pacificus in captivity. In: Recent advances in fisheries biology, edited by T. Okutani, R.K. O'Dor and T. Kubodera, Tokai University Press, Tokyo, pp. 179-187.

Jackson, G.D. and PV. Mladenov, 1994. Terminal spawning in the deepwater squid Moroteuthis ingens (Cephalopoda, Onychoteuthidae). I. Zool. Lond., Vol. 234, pp. 189-201.

Knipe, H.J. and R.D. Beeman, 1978. Histological observations on oogenesis in Loligo opalescens. Calif. Dept. Fish and Game, Fish Bull., Vol. 169, pp. 23-34. 
Lewis, A.R. and J.H. Choat, 1993. Spawning mode and reproductive output of the tropical cephalopod Idiosepius pygmaeus. Can. J. Fish. Aquat. Sci., Vol. 50, pp. 20-28.

Lum-Kong, A., 1993. Oogenesis, fecundity and pattern of spawning in Loligo forbesi (Cephalopoda: Loliginidae). Mal. Rev., Vol. 26, pp. 81-88.

Lum-Kong, A., G.J. Pierce and C. Yau, 1992. Timing of spawning and recruitment in Loligo forbesi (Cephalopoda: Loliginidae) in Scottish waters. J. Mar. Biol. Assoc. UK, Vol. 72, pp. 301-311.

McGowan, J.A., 1954. Observations on the sexual behavior and spawning of the squid, Loligo opalescens, at La Jolla, California. Calif. Fish and Game, Vol. 40, pp. 47-54.

Mangold, K., 1987. Reproduction. In: Cephalopods life cycles, edited by P.R. Boyle, Academic Press, I ondon, Vol. 2. Comparative Reviews, pp. 157-200.

Mangold, K, R.E. Young and M. Nixon, 1993. Growth versus Maturation in Cephalopods. In: Recent advances in fisheries biology, edited by T. Okutani, R.K. O'Dor and T. Kubodera, Tokai University Press, Tokyo, pp. $697-703$.

Mangold-Wirz, K., 1963. Biologie des Céphalopodes benthiques et nectoniques de la Mer Catalane. Vie Milieu, Vol. 13 (Suppl.), pp. 1-285.

Moreno, A., M.M. Cunha and J.M.F. Pereira, 1994. Population biology of veined squid (Loligo forbesi) and european squid (Loligo vulgaris) from the Portuguese coast. Fish. Res., Vol. 21, pp. 71-86.

O'Dor, R.K., 1983. Mlex illecebrosus. In: Cephalopods life cycles, edited by P.R. Boyle, Academic Press, London, Vol. 1. Species account, pp. 175-199.

Pierce, G.J., P.R. Boyle, L.C. Hastie, and L. Key, 1994. The life history of Loligo forbesi (Cephalopoda: Loliginidae) in Scottish waters. Fish. Res., Vol. 21, pp. 17-41

Natsukari, Y, and N. Komine, 1992. Age and growth estimation of the Furopean squid, Ioligo vulgaris, hased on statolith microstructure. J. Mar. Biol. Assoc. UK, Vol. 72, pp. 271-280.

Rasero, M., 1996. La pota Todaropsis eblanae (Ball, 1841) (Cephalopoda, Ommastrephidae): ciclo vital y aspectos ecológicos en las costas de Galicia. Doctoral Thesis, University of Santiago de Compostela. Santiago de Compostela, Spain. 233 pp.

Rocha, F., 1994. Aspectos biológicos y ecológicos de Loligo vulgaris y Loligo forbesi (Cephalopoda: Loliginidae) en las costas de Galicia (NW de España). Doctoral Thesis, University of Oviedo. Oviedo, Spain. $240 \mathrm{pp}$.

Rocha, F. and A. Guerra, in prep. Age and growth of two sympatric squids, Loligo vulgaris and Loligo forbesi in Galician waters: Comparison between statolith and modal progression analysis.

Rodaniche, A.F., 1984. Iteroparity in the lesser Pacific striped octopus Octopus chierchiae (Jatta, 1889). Bull. Mar. Sci., Vol. 35, pp. 99-104.

Sater, W.H. and M.R. Lipinski, 1990. Histological validation of morphological stages of sexual maturity in Chokker Squid Loligo vulgaris reynaudii D’Orb (Cephalopoda: Loliginidae). S. Afr. J. Mar. Sri., Vol. 9, pp. $189-200$.

Villanueva, R., 1992. Continuous spawning in the cirrate octopods Opisthoteuthis agassizii and O. vossi: features of sexual maturation defining a reproductive strategy in cephalopods. Mar. Biol, Vol, 114, pp. $265-275$.

Ward, P.D., 1987. The natural history of Nautilus. Allen and Unwin Inc., Boston, $267 \mathrm{pp}$.

Worms, J., 1983. Loligo vulgaris. In: Cephalopod life cycles, edited by P.R. Boyle, Academic Press, London, Vol. 1. Species Accounts, pp. 143-157. 